\title{
Centrifugal compressor efficiency improvement and its environmental impact in waste water treatment
}

J. Viholainen ${ }^{\text {a, }}{ }^{*}$, K. Grönman ${ }^{\text {a }}$, A. Jaatinen-Värri ${ }^{\text {a }}$, A. Grönman ${ }^{\text {a }}$, P. Ukkonen ${ }^{\text {b }}$, M. Luoranen ${ }^{\text {a }}$

${ }^{a}$ Lappeenranta University of Technology, P.O. Box 20, 53850, Lappeenranta, Finland.

${ }^{\mathrm{b}}$ Sulzer Pumps Finland, Turvekuja 6, 00700 Helsinki, Finland.

* Corresponding author. Tel.: +358 40 1795152; E-mail address: juha.viholainen@lut.fi (J. Viholainen).

\section{Abstract}

Energy costs typically dominate the life-cycle costs of centrifugal compressors used in various industrial and municipal processes, making the compressor an attractive target for energy efficiency improvements. This study considers the achievable energy savings of using three different diffuser types in a centrifugal compressor supporting a typical end-use process in a waste water treatment plant. The effect of the energy efficiency improvements on the annual energy use and the environmental impacts are demonstrated with energy calculations and lifecycle assessment considering the selected compressor task in the waste water aeration. Besides the achievable energy saving benefits in the wastewater aeration process, the presented study shows the influence of the additional material needed in the diffuser manufacturing on the total greenhouse gas emissions of the compressor life-cycle. According to the calculations and 
assessment results, the studied diffuser types have a significant effect on the compressor energy use and environmental impacts when the compressor is operated in the aeration task. The achievable annual energy savings in this case were $2.5-4.9 \%$ in comparison with the baseline scenario. Also, the influence of the additional material and energy use for manufacturing the diffuser is insignificant compared with the avoided greenhouse gas reduction potential.

Keywords: centrifugal compressor, energy efficiency, life-cycle assessment, waste water treatment

\section{Introduction}

The ongoing growth in global energy use, mainly based on fossil fuels, has increased the concentration of greenhouse gases in the atmosphere (Abdelaziz, et al., 2011). The continued greenhouse gas (GHG) emissions have shown to result in temperature increase in the Earth's climate leading to a pressing necessity to reduce the emissions (IPCC, 2007). In addition to the radical transform of the current energy systems to carbon neutral systems, the increase in both production and end-use energy efficiency are among the key options to achieve the required GHG reductions (Abdelaziz, et al., 2011; Saidur, 2010; IEA, 2012).

Electric motors are responsible for the major part of the electrical energy use in industrial countries. In the EU, the share of electric motors is approximately $70 \%$ of the total electricity consumption. (Ferreira, et al., 2011). Correspondingly, electric motor driven compressors are responsible for $18-25 \%$ of the industry's electricity use in the EU, which making the 
compressed-air systems an attractive target for energy efficiency improvements (Saidur, 2010; de Almeida, et al., 2003).

Centrifugal compressors are widely used for example in process industry, oil and gas industry, waste water treatment, and refrigeration processes. The benefits of centrifugal compressors compared with axial compressor are often related to robustness, wide operating range, and relatively low investment and maintenance costs (Schiffmann \& Favrat, 2010). When considering the overall lifetime costs of the compressed-air equipment, the energy costs typically dominate the life cycle costs (LCC) (Saidur, et al., 2010). According to Saidur et al. (2010), the energy costs can be up to $80 \%$ of the total life cycle costs. An example of life-cycle costs of a compressor is also shown in Fig. 1.

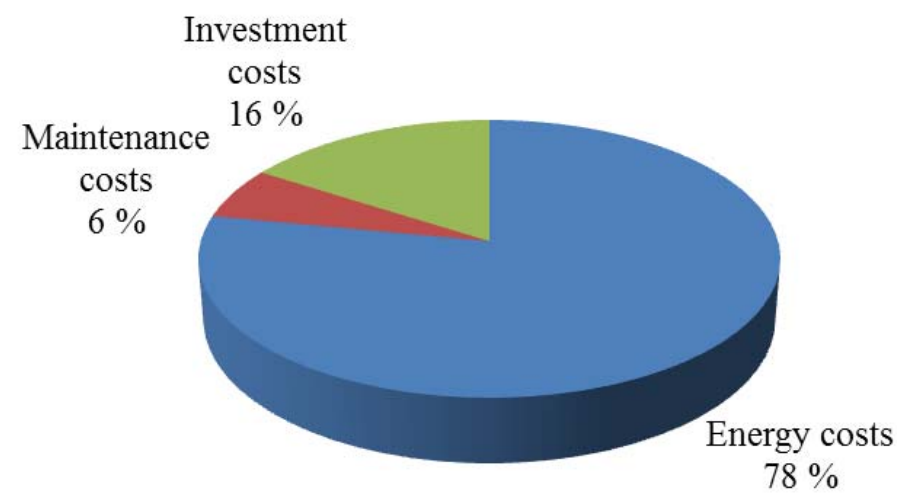

Fig. 1: Compressor life-cycle costs. The energy costs dominate the costs. (Saidur, et al., 2010)

In general, the actual energy used in the end-process can be only a fraction of the required primary energy when the whole energy chain is considered (Tolvanen, et al., 2013; Subramanyam, et al., 2015). Hence, the closer to the end-process the energy efficiency 
improvements are, the more effective they are in reducing energy-related emissions, as the saved energy in the end-process corresponds multiple times over to the need of primary energy. Different options for this kind of improvements in compressor processes can be categorized for example into improvements in the efficiency of the system components, justified component selection and system dimensioning, and the energy efficient adjustment of the system output.

A typical end-use process for centrifugal compressors is biological waste water treatment, where compressed air is required especially in the aeration in active sludge tanks. In such waste water treatment plants, the aeration is typically the most energy-intensive process stage (Chew \& Kang, 2013), and the compressors can be responsible for almost $70 \%$ of the total electricity use at the facility (Descoins, et al., 2012). Typically, the aeration process is constantly alive, and as a result the annual downtime of the compressors is very low. Additionally, the required compressor pressure ratio is often constant, as the compressor discharge pressure is dictated mainly by the piping pressure losses and, more importantly, the water level in aeration tanks. These characteristics clearly demonstrate, not only the significance of the justified dimensioning of the system, but also the importance of the high compressor efficiency at the actual, required operation range.

Concerning the energy efficiency of a centrifugal compressor, the performance of a centrifugal compressor impeller has reached a very high level, and much of the potential for further improvements lie in the diffuser development as discussed by Kim et al. (2002) and Issac et al. (2003). In general, there are three main types of diffuser designs: vaneless diffuser (VNLD), low solidity vaned diffuser (LSD) and vaned diffuser (VND), all of which have different influences 
on the overall compressor performance and the width of the operating map. Correspondingly, all of these diffuser designs have varying material requirements in manufacturing; a point which is often not thoroughly considered from the life cycle point of view.

In this paper, these three diffuser types are studied from energy conversion and life cycle point of view. The main aim of the study is, not only to demonstrate the energy efficiency benefits of each diffuser type, but also to indicate the environmental impacts of these energy efficiency improvements in a compressor process. Therefore, the use of the different diffuser designs is studied in an example case consisting of a centrifugal compressor supporting the aeration process in a waste water treatment plant. For the assessment of the environmental impacts of the different diffuser designs, an LCA (life cycle assessment) study is conducted. The aim is to analyze 1) how much the improvement in energy efficiency of the compressor using different diffuser designs reduces the greenhouse gas emissions and 2) does the additional material needed in diffuser manufacturing have an effect on the total greenhouse gas emissions? Hence, the second research question can also be formulated as: Is improving the energy efficiency of a compressor reasonable if it requires more material in the compressor manufacturing?

Although this paper concentrates on energy efficiency improvements in the component design, the energy conversion of the compressor is not the only relevant indicator when evaluating the energy efficiency of the waste water treatment process or aeration stage. The overall energy efficiency is also affected for instance, by the dimensioning of the compressor system, leakages in the air ducts, distribution losses when delivering air into the tanks, and the efficiency of the aeration itself. In addition, the same compressed air delivered by the compressor units is 
typically used in many other process stages in the plant. As this study focuses on the energy use and the LCA study on compressor diffuser designs, other aspects affecting the aeration efficiency are excluded.

The paper is organized as follows: first, the energy efficiency improvement scenarios related to different diffuser designs are being discussed. The next section introduces a compressor task in a waste water treatment plant illustrating a typical end-use process for centrifugal compressors. The section also presents the resulting energy consumption and potential savings with each diffuser scenario. Based on these energy calculations, the life-cycle assessment study is conducted. Finally, conclusions of this study are given in the last section.

\section{Studied efficiency improvement scenarios for centrifugal compressors}

As mentioned, the centrifugal compressor performance can be affected with three main diffuser types: vaneless diffuser, low solidity vaned diffuser, and vaned diffuser. Additionally, the vaneless diffuser can be modified by pinch to improve the performance, which means narrowing the height of the diffuser compared to the impeller blade height. A schematic view of different diffuser designs is given in Fig. 2. 


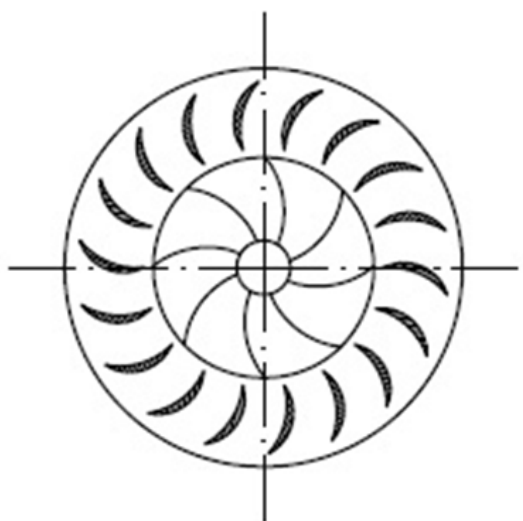

(a)

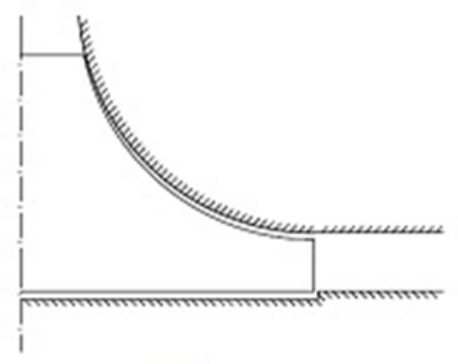

(c)

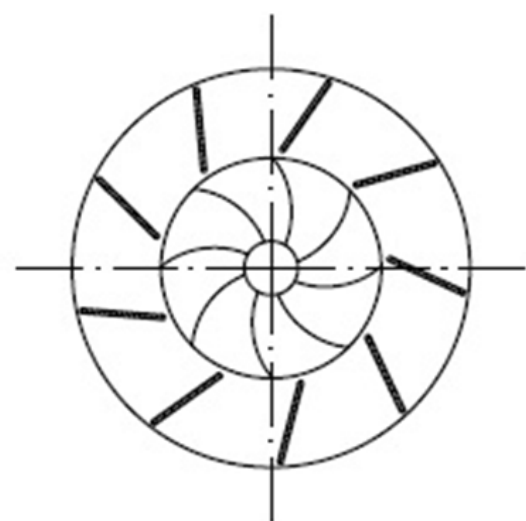

(b)

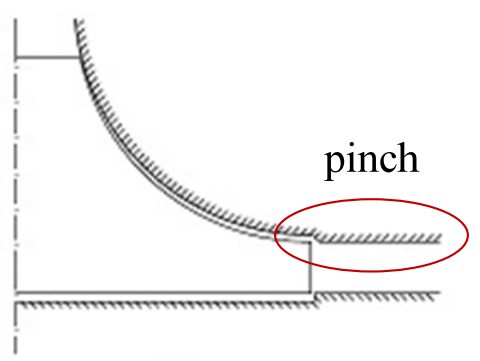

(d)

Fig. 2: A schematic view of different diffuser designs (a) vaned diffuser, (b) low solidity vaned diffuser with flat plate vanes, (c) unpinched vaneless diffuser, and (d) pinched vaneless diffuser

The presented diffuser designs can be studied in terms of efficiency improvement and material resource requirements. In this study, the presumed material for each diffuser scenario is Aluminum (AlMg3). The diffuser scenarios are categorized into pinched diffuser (PND, Scenario 1), low solidity diffuser (Scenario 2), and vaned diffuser (Scenario 3). These three diffuser scenarios are compared with the selected baseline of the vaneless design (VNLD) of Scenario 0. 
Scenario 1 represents the use of moderate pinch in the diffuser, where the diffuser passage height is narrowed from the nominal height. Pinched diffuser (PND) is known to improve the efficiency of a centrifugal compressor and still maintain an almost similar operating map width as a vaneless diffuser (Jaatinen, et al., 2011). Scenario 2 considers the low solidity diffuser (LSD), where no geometrical throat is formed between the two vanes due to low number of short vanes. The LSD represents also higher efficiencies than the vaneless diffuser and it maintains the width of the operating map usually very well (Grönman, et al., 2013). Although the vaned diffuser (VND) in Scenario 3 has usually the highest performance improvement of the different diffuser designs, the width of the operating map is clearly narrower than with the other designs. The narrower operating range is mainly due to two reasons: the diffuser vanes are sensitive to the changing incidence, and they form an aerodynamic throat, which limits the maximum mass flow. The incidence influences also the vanes in the LSD; however they are considered to be mostly guiding the flow instead of diffusing it and are therefore not that sensitive. In addition, the vanes in the low solidity diffuser do not form an aerodynamic throat; hence, the maximum mass flow is dictated by the impeller as in the vaneless diffuser.

In comparison with the vaneless diffuser Fig. 3 illustrates the efficiency improvements for different diffuser designs at the compressor nominal speed (Hayami, et al., 1989; Hohlweg, et al., 1993; Amieni, et al., 1996; Kmecl, et al., 1999; Engeda, 2001; Reddy, et al., 2007; JaatinenVärri, et al., 2013; Jaatinen-Värri, et al., 2014). It can be interpreted from the figure that the average estimation for the efficiency by using pinched diffuser is 1.03 times the vaneless diffuser efficiency. For the low solidity diffuser and vaned diffuser the improvements are 1.04 and 1.05, respectively. 


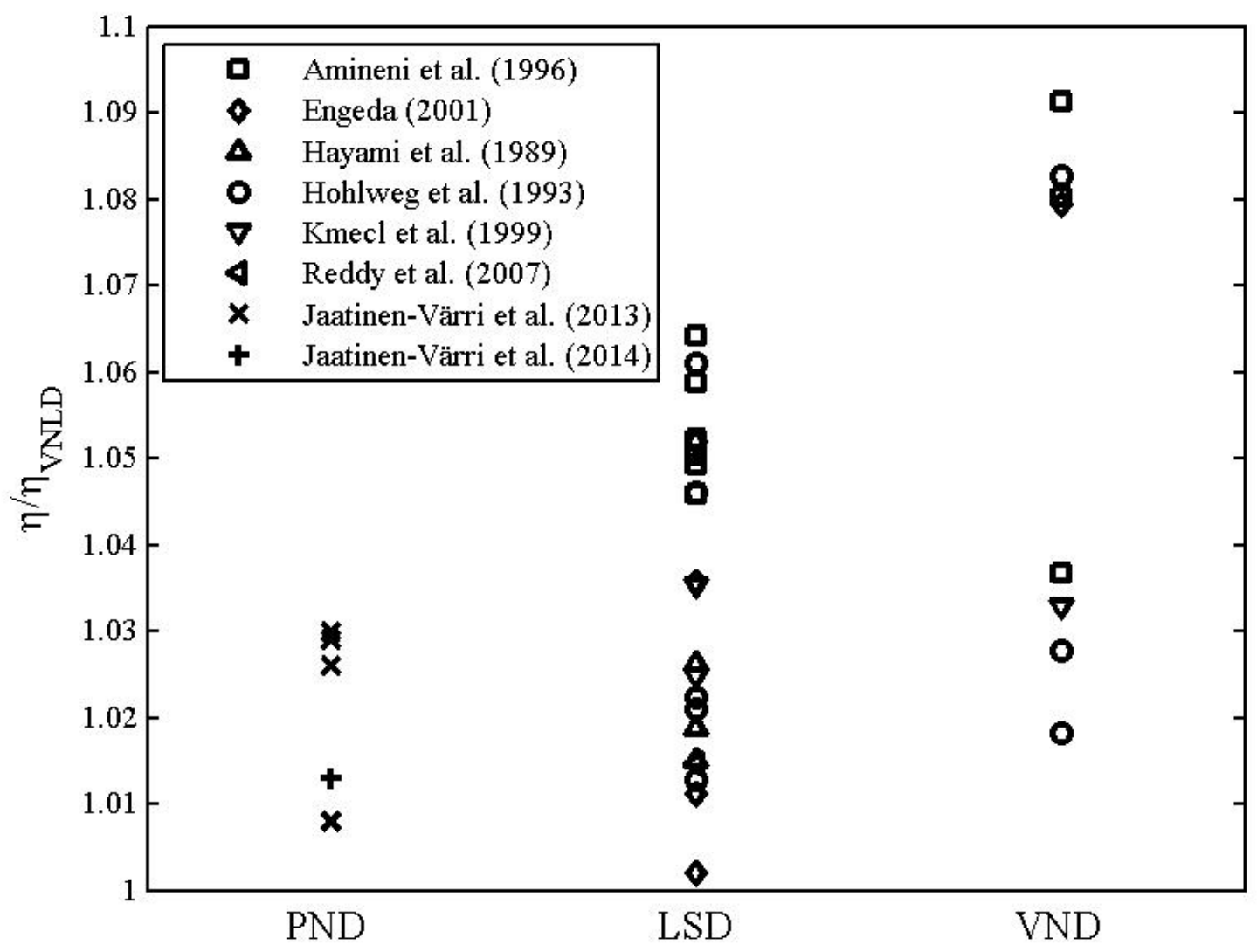

Fig. 3: Influence of diffuser type on the peak efficiency at the nominal speed. Pinched diffuser (PND), low solidity diffuser (LSD) and vaned diffuser (VND) are compared with the vaneless diffuser.

\section{Studied compressor task and resulting energy use for the improvement scenarios}

To demonstrate the energy use of the selected compressor scenarios in an actual end-use process, the scenario characteristics were applied in a compressor task of a waste-water treatment plant (WWTP) in Lappeenranta, Finland. The amount of treated waste water at the plant has ranged in recent years between $5400000 \mathrm{~m}^{3} / \mathrm{a}$ and $6800000 \mathrm{~m}^{3} / \mathrm{a}$. At the example plant, compressed air is required in two active sludge tanks, both of which can be described as a primary process for 
the compressed air. Besides the primary process, compressed air is delivered to sand separation, septic tank, and mixing and stabilization basins, all of which can be described as supporting processes. The layout of the compressed air system at the plant is shown in Fig. 4.

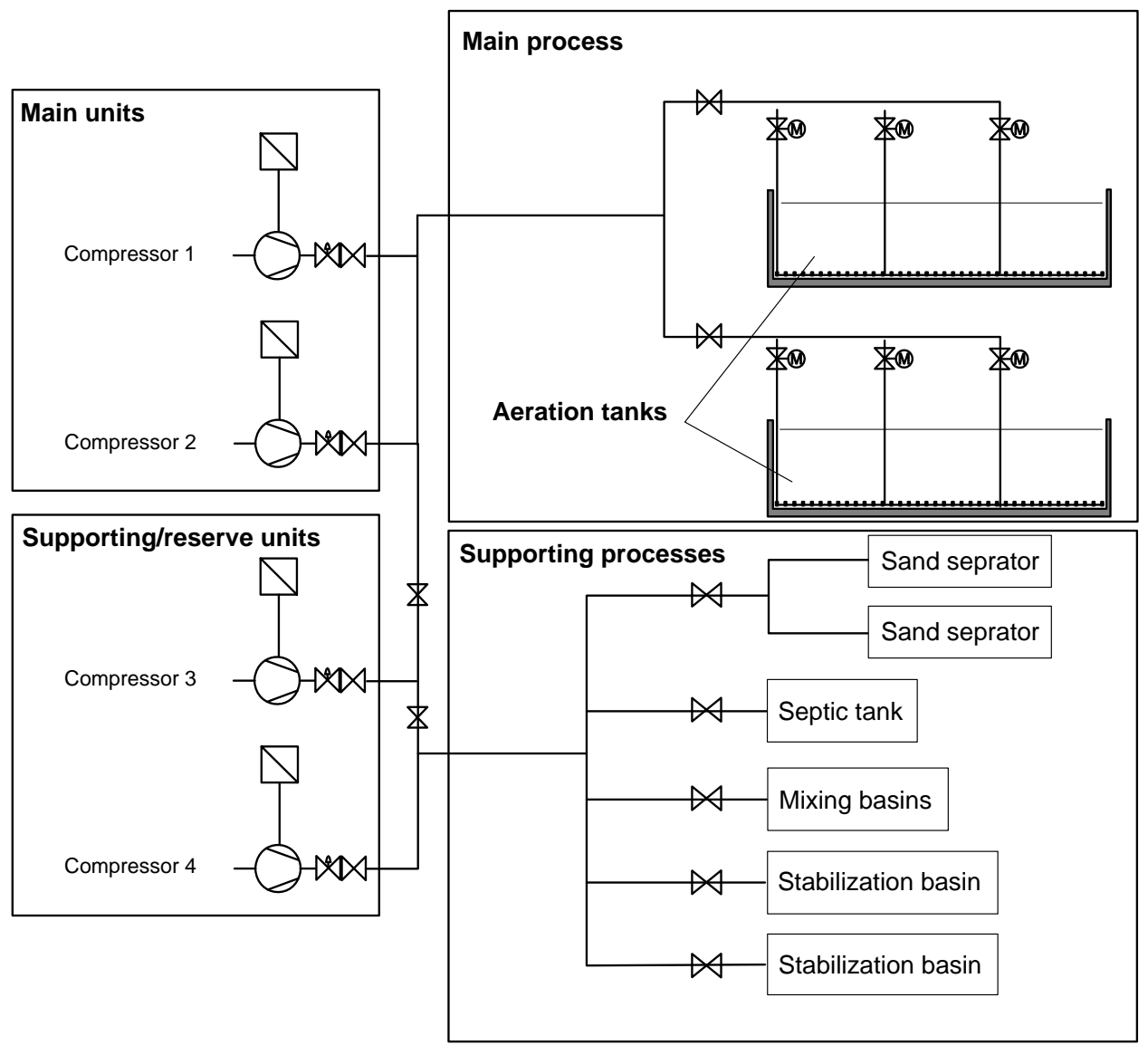

Fig. 4: Compressed air system at the waste water treatment plant.

The compressed air system consists of four compressor units delivering air to the aeration tanks and to the supporting process (Fig. 4). The required total amount of air can be generated using two or three compressors in parallel, while the remaining units can be used as a reserve. Typically, the facility uses $5700000-7000000 \mathrm{Nm}^{3}$ air monthly, $60-65 \%$ of which goes to the aeration tanks. 


\subsection{Aeration compressor operating map}

The energy calculations based on the compressor improvement scenarios focus on a centrifugal compressor delivering air in the primary process of the illustrated system in Fig. 4. In this example case, the operating range for the compressor is approximately $1.42 \mathrm{~kg} / \mathrm{s}-1.62 \mathrm{~kg} / \mathrm{s}$ with the pressure ratio of 1.47 . The operating range varies according to the incoming waste water and the process conditions. Based on the operation during 2013 and 2014, the monthly average output for a single compressor is $1.52 \mathrm{~kg} / \mathrm{s}$. The pressure ratio remains practically constant since the system pressure is mainly dictated by the constant water level in the aeration tanks. In the waste water plant, the running hours for the main process compressor is approximately $8760 \mathrm{~h} / \mathrm{a}$, as the running time is only limited by possibly occurring power failures or maintenance needs. In this case, however, the probability for a power failure and maintenance needs can be considered equal in each scenario, and are therefore neglected.

Fig. 5 presents the monthly average compressor operating conditions during ten months of operation in 2013 and 2014. Because of the relatively narrow operating range, it can be estimated that the compressor is operated close to its maximum efficiency despite the small changes in the compressor output. Therefore, the approximation for the increased compressor efficiency in the case of Scenarios 1-3 interpreted earlier from Fig. 3 can be considered acceptable for the current case study. 


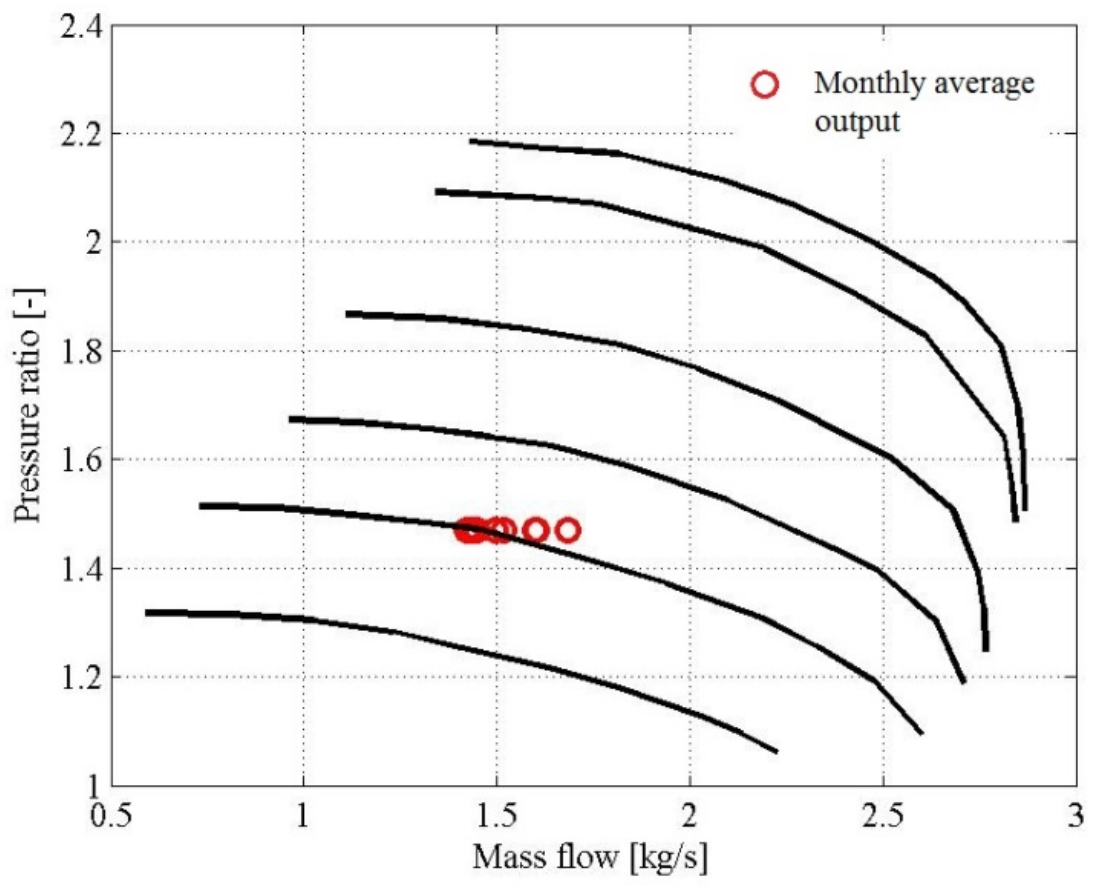

Fig. 5: Monthly average output of the compressor supporting the aeration process

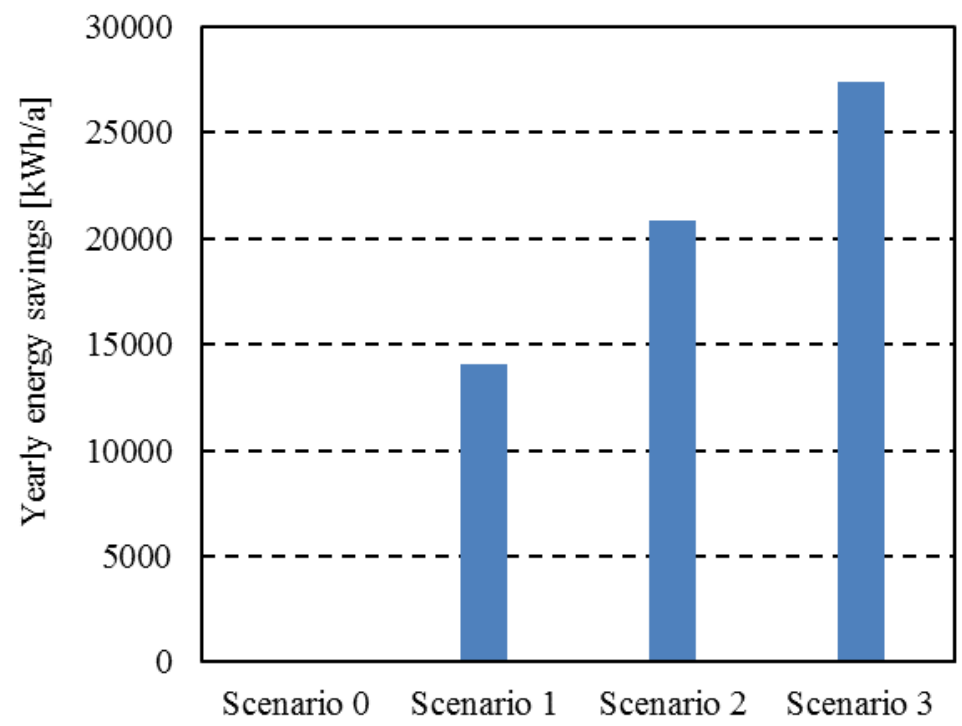

Fig. 6: Annual energy savings with different scenarios compared to Scenario 0. 


\section{Table 1}

Required output and the resulting annual energy consumption for the primary process compressor

\begin{tabular}{|c|c|c|c|c|c|c|}
\hline & \multicolumn{3}{|c|}{ Mass } & \multicolumn{3}{|c|}{ Energy } \\
\hline & $\pi$ & $\begin{array}{l}\text { flow } \\
(\mathrm{kg} / \mathrm{s})\end{array}$ & $\eta / \eta \mathrm{VNLD}$ & $\begin{array}{l}\text { Operating } \\
\text { hours }(\mathrm{h} / \mathrm{a})\end{array}$ & $\begin{array}{c}\text { consumption } \\
(\mathrm{MWh} / \mathrm{a})\end{array}$ & $\begin{array}{l}\text { Energy } \\
\text { savings }\end{array}$ \\
\hline Scenario 0 & 1.47 & 1.52 & 1.00 & 8760 & 562 & - \\
\hline Scenario 1,PND & 1.47 & 1.52 & 1.03 & 8760 & 548 & $2.5 \%$ \\
\hline Scenario 2, LSD & 1.47 & 1.52 & 1.04 & 8760 & 541 & $3.7 \%$ \\
\hline Scenario $3, \mathrm{VND}$ & 1.47 & 1.52 & 1.05 & 8760 & 535 & $4.9 \%$ \\
\hline
\end{tabular}

\subsection{Energy calculations based on the required output}

The calculated annual energy consumptions for each scenario based on the required average output and the compressor characteristics are presented in Table. 1. The annual energy savings of the different scenarios are show in Fig. 6

As shown in Table 1, the energy efficiency improvements in a compressor can have a significant effect on the annual energy use in the example end-use process. The presented energy savings of Scenarios 1-3 in Fig. 6 suggest that the potentially saved energy costs for a single compressor can range approximately from $1400 € /$ a to $2700 € / \mathrm{a}$, if the electricity price is $0.10 € / \mathrm{kWh}$. Since the additional material and manufacturing costs are highest for Scenario 3, where they are little over $1000 €$, the payback time will be less than one year. 
The average energy consumption per treated cubic meter in the WWTPs in the EU varies moderately according to for instance different techniques, plant characteristics, and size, while the energy consumption ranges typically between $0.3 \mathrm{kWh} / \mathrm{m}^{3}$ and $0.6 \mathrm{kWh} / \mathrm{m}^{3}$ (Venkatesh \& Brattebø, 2010; Hernández-Sancho, et al., 2011; Plappally \& Lienhard V, 2012; Frijns, et al., 2013). Besides the aeration, energy is used in pumping, mixing, sludge handling, space heating, lightning, and maintenance at the waste water treatment plant.

The regional potential for energy efficiency improvements with the presented compressor scenarios in urban waste water treatment processes in the EU can be estimated roughly as follows. First, the energy consumption of the aeration stage is estimated to be $50-60 \%$ of the total WWTP energy consumption as discussed by Hernández-Sancho et al. (2011). The average specific energy consumption for treated waste water in this case is approximated to be 0.45 $\mathrm{kWh} / \mathrm{m}^{3}$. Finally, a rough estimation for the incoming waste water can be predicted based on the statistics: at least 30000 million cubic meters of waste water is treated in the EU every year (FAO, 2014; EUROSTAT, 2010). Therefore, the resulting energy use for treated waste water would be not less than $13500 \mathrm{GWh} / \mathrm{a}$, of which the share of the aeration would then be 6750 $\mathrm{GWh} / \mathrm{a}-8100 \mathrm{GWh} / \mathrm{a}$. As the theoretical energy savings in the presented scenarios varied between $2.5 \%$ and $4.9 \%$, the saved energy in the EU region WWTP plants would equal roughly to $170 \mathrm{GWh} / \mathrm{a}-400 \mathrm{GWh} / \mathrm{a}$.

The calculated energy saving potential of the presented scenarios in the EU region WWTPs can be considered speculative. Even though giving a rather pessimistic magnitude for the potential 
savings in WWTP related compressor end-processes, it shows the significance of the energy efficiency procedures in the observed process branch's scale.

\section{Life cycle assessment for different diffuser scenarios}

In this section, the environmental impact of the presented compressor scenarios is being studied. The LCA study is based on the energy calculations in the previous section for a single compressor supporting the end-use process in the example waste water treatment plant.

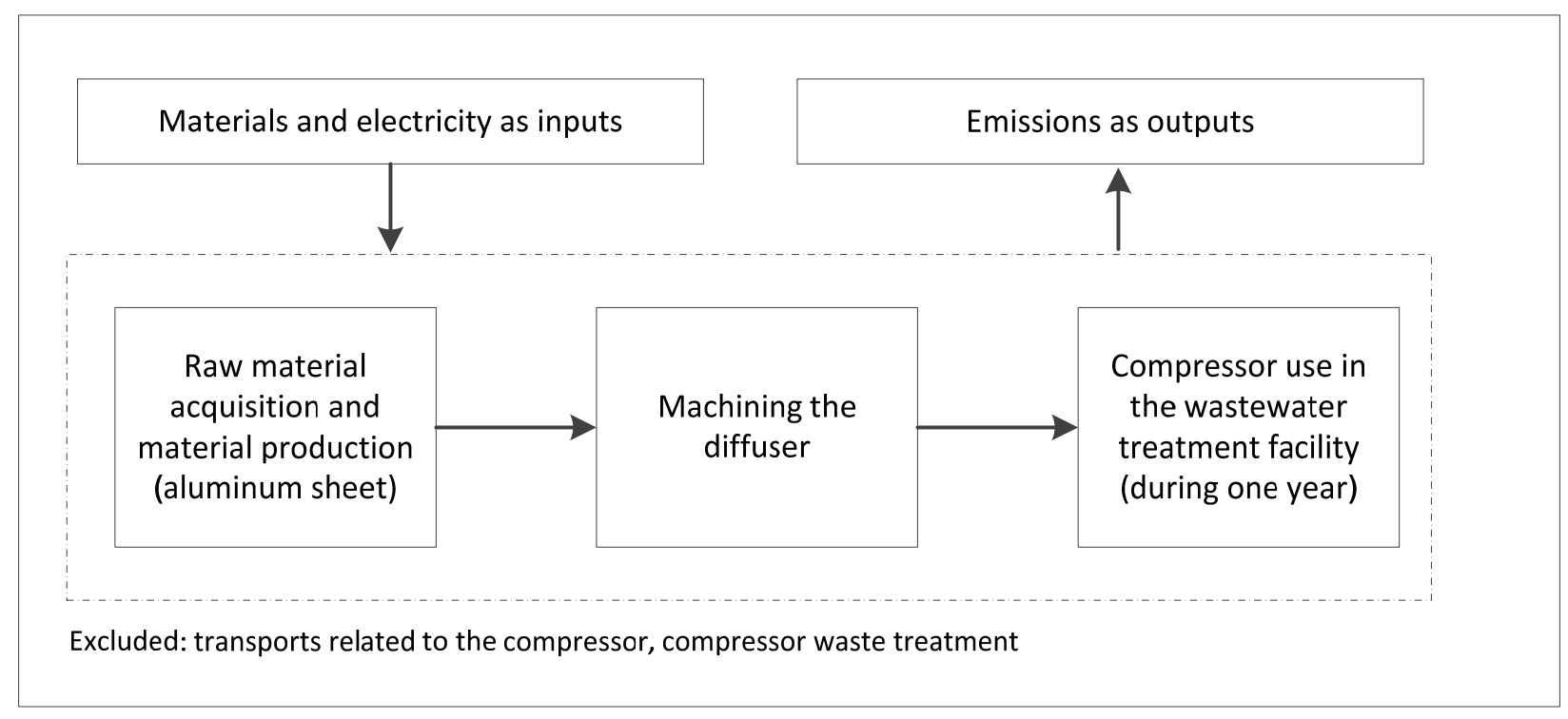

Fig. 7: System boundaries of the LCA study 


\subsection{Methodology for the LCA study}

The functional unit of the LCA study is a single centrifugal compressor discussed in previous section, and it is used in a waste water treatment facility for a time span of one year. The system boundaries of the LCA study are presented in Fig. 7.

The LCA study concentrates only on the values that differ between the different diffuser design scenarios. Thus, the main differences are in the amount of aluminum sheet needed to manufacture the diffuser in Scenarios $0-3$ as well as the annual electricity consumption during the compressor's use phase. Also, the varying electricity consumption when machining the diffusers is taken into account. The other parts in the studied compressor remain the same; thus, they are excluded from the study. As mentioned earlier, the assumption is that there is no difference between the service life and the maintenance needs of the compressors in scenarios $0-3$, and therefore they are not taken into account. The waste treatment of the diffuser is excluded, as the focus of this study is on the production and use phases. Transporting the aluminum sheet to the diffuser manufacturing as well as transporting the diffuser to the location of use is excluded because the transported masses are negligible in the case of only one diffuser.

The data used for the aluminum sheet (AlMg3) production represents the cradle-to-gate inventory data from the average European aluminum industry ( $\mathrm{GaBi}, 2012)$. The amount of aluminum needed in different diffuser scenarios is presented in Table 2. Apart from the aluminum sheet, no other materials are required in the machining of the diffuser. The electricity use for diffuser machining is derived from the estimated electricity consumption of a suitable milling machine. The annual electricity consumption during the compressor use phase for 
different scenarios was calculated in the previous section. The life cycle inventory data on electricity represents the average Finnish electricity production (GaBi, 2012).

\section{Table 2}

Amount of Aluminum and the machining energy consumption for the diffuser scenarios

\begin{tabular}{lccc}
\hline & Raw material & Loss & Manufacturing \\
\hline Scenario 0 & $4.08 \mathrm{~kg}$ & $2.06 \mathrm{~kg}$ & $10 \mathrm{kWh}$ \\
Scenario 1,PND & $6.53 \mathrm{~kg}$ & $3.66 \mathrm{~kg}$ & $10 \mathrm{kWh}$ \\
Scenario 2, LSD & $16.34 \mathrm{~kg}$ & $13.54 \mathrm{~kg}$ & $50 \mathrm{kWh}$ \\
Scenario 3, VND & $16.34 \mathrm{~kg}$ & $13.24 \mathrm{~kg}$ & $50 \mathrm{kWh}$ \\
\hline
\end{tabular}

The LCA study was conducted using GaBi 6 life cycle modelling tool. The study was done in compliance with the ISO standards 14040 (SFS-EN ISO 14040, 2006) and 14044 (SFS-EN ISO 14044, 2006). The global warming potential was the studied environmental impact category using the CML method's characterization factors from November 2010 (Guinée, et al., 2002).

\subsection{LCA results}

In Fig. 8, the global warming potential results are presented for the diffusers Scenarios 0-3. As can be seen, with different diffuser designs that reduce electricity consumption during the compressor use, the global warming potential of the studied system is decreasing. The greatest savings in energy consumption and thus in greenhouse gas emissions result from Scenario 3, where the vaned diffuser is used. This saving is nearly $5 \%$ of the total GHG emissions of 
Scenario 0 where the baseline, the vaneless diffuser, is used. In a larger context, the $9.6 \mathrm{tCO}_{2}$-eq. saving is also equivalent to the average annual greenhouse gas emissions per capita in the EU-15 countries in 2010 (EAA, 2012).

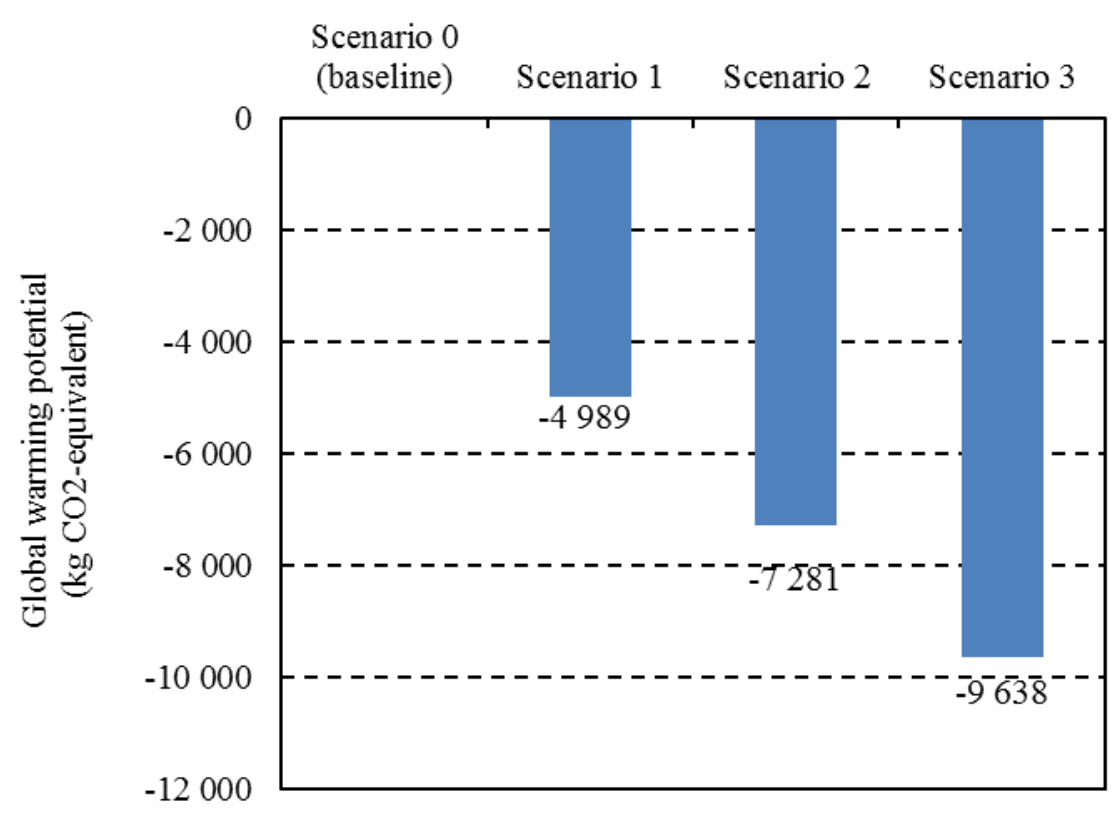

Fig. 8: Savings in greenhouse gas emissions due improved energy efficiency in diffuser design scenarios. Scenarios 1-3 are compared with the baseline (Scenario 0)

Table 3 presents the global warming potentials of different scenarios divided into manufacturing the diffuser out of aluminum and the use of the compressor in a wastewater treatment facility during one year. It can be seen that even if the amount of aluminum is increased in Scenarios 1-3 compared to the baseline diffuser, its share of the total global warming potential is minimal. The share of aluminum's global warming potential would further decrease if it would be compared to the actual life time emissions of a compressor rather than the emissions caused during one year of operation. Given the findings, it can be concluded that improving the energy 
efficiency of a compressor is sensible even though more energy efficient diffuser structures require more aluminum.

\section{Table 3}

Shares of aluminum sheet production and diffuser machining as well as the compressor's annual energy consumption (use phase) of the global warming potential.

\begin{tabular}{lcc}
\hline & \multicolumn{2}{c}{ Global warming potential } \\
& Diffuser & Use phase \\
& manufacturing & \\
\hline Scenario 0, VNLD & $0.024 \%$ & $99.976 \%$ \\
Scenario 1, PND & $0.039 \%$ & $99.961 \%$ \\
Scenario 2, LSD & $0.103 \%$ & $99.897 \%$ \\
Scenario 3, VND & $0.104 \%$ & $99.896 \%$ \\
\hline
\end{tabular}

\section{Conclusions}

The growing interest of increasing the energy efficiency in processes applying centrifugal compressors sets challenges at different solution levels including the design of more energy efficient components, dimensioning and selection of the components according to process needs, and the energy efficient use and control of the supported fluid handling task. This study gives an illustration on how the energy efficiency improvements particularly in the component design are 
related to the energy use and generated greenhouse gases in a typical end-use process for compressors.

In this study, three different centrifugal compressor diffuser scenarios were compared in terms of energy consumption and greenhouse gas savings in an example case of supporting the aeration process in a waste water treatment plant. The results clearly indicate that improvements in the energy efficiency of the compressor using pinched diffuser, low solidity vaneless diffuser, or vaned diffuser, have a significant effect on the total energy use in the aeration process. In the presented example process task, the energy savings ranged between $2.5 \%$ and $4.9 \%$ in the annual energy use, resulting approximately in an $1400 €-2700 €$ reduction in the energy costs every year with an additional investment of little over $1000 €$. Although representing only the energy saving potential in a system-specific case, the targeted example illustrates a very typical end-use process for centrifugal compressors. Notably, the calculated savings are also in line with the recognized potential of achieving energy efficiency with compressor designs in the EU region (Raudgen \& Blaustein, 2001; Saidur, et al., 2010).

Based on the conducted LCA study, the results give a strong indication that for the aeration compressor, the additional material needed in the diffuser manufacturing has an insignificant influence on the total greenhouse gas emissions. It is also shown, that selecting the diffuser design has a large influence on the resulting greenhouse gas emissions for the studied case. However, when choosing an aeration compressor it is important to evaluate the range of the required operating map and study whether there is a risk of operating close to the choke and surge limits. Although this may exclude especially the use of vaned diffuser in some cases, the 
use of a pinch or low solidity vaned diffuser will be in the scope of most of the waste water treatment plants due to their wide operating maps.

In the processes where the machine is operated continuously, the energy consumption is by far the largest factor in life-cycle costs. Therefore, even a seemingly small efficiency improvement can have a substantial effect on the environmental impacts of the machine operation. In this study, for a single compressor the annual reduction in greenhouse gas emissions ranged from $5 \mathrm{t}$ $\mathrm{CO}_{2}$-eq to $9.5 \mathrm{t} \mathrm{CO}_{2}$-eq. In case of the scenario with the highest energy saving potential, Scenario 3 (VNLD), the price for the avoided $\mathrm{CO}_{2}$-emissions would be roughly $0.10 € / \mathrm{kg}_{\mathrm{c}_{2}}$. The example waste water treatment plant has two to three compressors running simultaneously, so the savings would actually be two to threefold. It should be noted, however, that the energy savings are always system specific, and depend on the required output. In certain treatment plants, the required output for the compressor can have wider variation compared with the example case, which naturally should be taken into account when considering the component selection, dimensioning and control aspects.

Since the focus of this paper is limited to study the effect of diffuser scenarios in actual process use, it does not attempt to identify solutions having the highest or most cost-effective potential for reducing energy consumption and greenhouse gas emissions in WWTPs. This would require a systematic approach on the technical solutions and energy use during each treatment phase including process dimensioning and control options. In addition, the energy efficiency of the waste water treatment process should be evaluated considering the distribution of air and the 
aeration efficiency in the aeration tanks taking into account whether the compressed air system is delivering air to other process stages.

With this study, the authors present a solid argument for the importance of studying the operating costs of a compressor during the entire lifetime when selecting the operating components for the aeration process. In other words, the presented example case demonstrates that although the energy efficiency improvement may bring extra costs to the investment due to additional material use, machinery, or other resources, it can be insignificant when compared with the life time operating costs and environmental impact.

\section{References}

Abdelaziz, E. A., Saidur, R. \& Mekhilef, S., 2011. A review on energy saving strategies in industrial sector. Renewable and Sustainable Energy Reviews, 15(2011), p. 150-168.

Amieni, N. K., Engeda, A., Hohlweg, W. C. \& Direnzi, G. L., 1996. Performance of Low Solidity and Conventional Diffuser Systems for Centrifugal Compressors, s.1.: s.n.

Chew, K.-J. \& Kang, J., 2013. Estimating the energy independence of a municipal wastewater treatment plant incorporating green energy resources. Energy Conversion and Management, 75(2013), pp. 664-672.

de Almeida, A. T., Fonseca, P., Falkner, H. \& Bertoldi, P., 2003. Market transformation of energy-efficient motor technologies in the EU. Energy Policy, 31(6), p. 563-575.

Descoins, N. et al., 2012. Energy efficiency in waste water treatments plants: Optimization of activated sludge process coupled with anaerobic digestion. Energy, 41(2012), pp. 153-164. 
EAA, 2012. Greenhouse gas emission trends and projections in Europe 2012. Tracking progress towards Kyoto and 2020 targets, s.1.: s.n.

Engeda, A., 2001. The Design and Performance Results of Simple Flat Plate Low Solidity Vaned Diffusers. Proc. IMechE, Part A: Journal of Power and Energy, Volume 215, pp. 109-118.

EUROSTAT, 2010. Environmental statistics and accounts in Europe, Luxembourg: Publications Office of the European Union.

FAO, 2014. AQUASTAT database, Food and Agriculture Organization of the United Nations (FAO). [Online]

[Accessed 3110 2014].

Ferreira, F. J. T. E., Fong, C. \& de Almeida, T., 2011. Eco-analysis of Variable-Speed Drives for Flow Regulation in Pumping Systems. IEEE Transactions on Industrial Electronics, 58(6).

Frijns, J., Hofman, J. \& Nederlof, M., 2013. The potential of (waste)water as energy carrier. Energy Conversion and Management, 65(2013), pp. 357-363.

GaBi, 2012. PE International: GaBi 6 software-system and databases. In: s.1.:s.n.

Grönman, A., Dietmann, F., Casey, M. \& Backman, J., 2013. Review and Collection of Preliminary Design Rules for Low Solidity Diffusers. Lappeenranta, Finland, s.n.

Guinée, J. B. et al., 2002. Handbook on life cycle assesment. Operational guide to the ISO standards. I:LCA in perspective. IIa: Guide. IIb: Operational annex. III: Scientific background. Dordrecht: Kluwer Academic Publishers.

Hayami, H., Senoo, Y. \& Utsunomiya, K., 1989. Application of Low-Solidity Cascade Diffuser to Transonic Centrifugal Compressor, s.1.: s.n. 
Hernández-Sancho, F., Molinos-Senante, M. \& Sala-Garrido, R., 2011. Energy efficiency in Spanish wastewater treatment plants: A non-radial DEA approach. Science of the Total Environment, 409(2011), pp. 2693-2699.

Hohlweg, C., Direnzi, G. L. \& Aungier, R. H., 1993. Comparison of Conventional and Low Solidity Vaned Diffusers, s.1.: s.n.

IEA, 2012. World Energy Outlook 2012, Paris, France: IEA Publications.

IPCC, 2007. Climate Change 2007: Synthesis Report, Geneva, Switzerland: Intergovernmental Panel of Climatic Change.

Issac, J. M., Sitaram, N. \& Govardhan, M., 2003. Performance and Wall Static Pressure Measurements on Centrifugal Compressor Diffusers. Proc. IMechE, Part A: Journal of Power and Energy, Volume 217, pp. 547-558.

Jaatinen, A., Grönman, A., Röyttä, P. \& Turunen-Saaresti, T., 2011. Effect of Vaneless Diffuser Width on the Overall Performance of a Centrifugal Compressor. Proc. IMechE, Part A: Journal of Power and Energy, Volume 225, pp. 665-676.

Jaatinen-Värri, A., Grönman, A., Turunen-Saaresti, T. \& Backman, J., 2014. Investigation of the Stage Performance and Flow Fields in a Centrifugal Compressor with a Vaneless Diffuser. International Journal of Rotating Machinery, Volume 2014.

Jaatinen-Värri, A., Röyttä, P., Turunen-Saaresti, T. \& Grönman, A., 2013. Experimental Study of Centrifugal Compressor Vaneless Diffuser Width. Journal of Mechanical Science and Technology, Volume 27, pp. 1011-1020. 
Kim, Y., Engeda, A., Aungier, R. \& Amineni, N. A., 2002. Centrifugal Compressor Stage with Wide Flow Range Vaned Diffusers and Different Inlet Configurations. Proc. IMechE, Part A: Journal of Power and Energy, Volume 216, pp. 307-320.

Kmecl, T., Ter Harkel, R. \& Dalbert, P., 1999. Optimization of a Vaned Diffuser Geometry for Radial Compressors, Part II: Optimization of a Diffuser Vane Profile in Low Solidity Diffusers, s.l.: s.n.

Plappally, A. K. \& Lienhard V, J. H., 2012. Energy requirements for water production, treatment, end use, reclamation, and disposal. Renewable and Sustainable Energy Reviews, 16(2012), pp. 4818-4848.

Raudgen, P. \& Blaustein, E., 2001. Compressed Air Systems in the European Union. Energy, Emissions, Savings Potential and Policy Actions, Stuttgart, Germany: LOG_X Verlag GmbH.

Reddy, S. T. C., Ramana Murty, G. V., Prasad, M. V. S. S. S. M. \& Reddy, D. N., 2007. Experimental Studies on the Effect of Impeller Width on Centrifugal Compressor Stage Performance with Low Solidity Vaned Diffusers. Proc. IMechE, Part A: Journal of Power and Energy, 221(4), pp. 519-533.

Saidur, R., 2010. Review on electric motors energy use and energy savings. Renewable and Sustainable Energy Reviews, 14(2010), p. 877-898.

Saidur, R., Rahim, N. A. \& Hasanuzzaman, M., 2010. A review on compressed-air energy use and energy savings. Renewable and Sustainable Energy Reviews, 14(2010), pp. 1135-1153.

Schiffmann, J. \& Favrat, D., 2010. Design, experimental investigation and multi-objective optimization of a small-scale radial compressor for heat pump applications. Energy, 35(2010), pp. 436-450. 
SFS-EN ISO 14040, 2006. Environmental management. Life cycle assesment. Principles and framework.. In: Helsinki: Finnish Standards Association.

SFS-EN ISO 14044, 2006. Environmental management. Life cycle assesment. Requirements and guidelines.. In: Helsinki: Finnish Standards Association.

Subramanyam, V., Parashivan, D., Kumar, A. \& Mondal, M. A. H., 2015. Using Sankey diagrams to map energy flow from primary fuel to end use. Energy Conversion and Management, 91(2015), pp. 342-352.

Tolvanen, J., Ahonen, T. \& Kervinen, H., 2013. System optimization through co-operation, Helsinki, Finland: ABB OY.

Venkatesh, G. \& Brattebø, H., 2010. Energy consumption, costs and environmental impacts for urban water cycle services: Case study of Oslo (Norway). Energy, 36(2011), pp. 792-800. 